\title{
A Study on the Metacognitive Awareness of Secondary School Students
}

\author{
Sajna Jaleel ${ }^{*}$, Premachandran. P \\ School of Pedagogical Sciences, M.G University, India
}

Copyright (C) 2016 by authors, all rights reserved. Authors agree that this article remains permanently open access under the terms of the Creative Commons Attribution License 4.0 International License

\begin{abstract}
Metacognition means "thinking about one's own thinking". There are two aspects of metacognition: reflection- thinking about what we know and self-regulationmanaging how we go about learning. Taking together, these processes make up an important aspect of learning and development. Developing these metacognitive abilities is not simply about becoming reflective learners, but about acquiring specific learning strategies as well. Metacognitive beliefs, metacognitive awareness, metacognitive experiences, metacognitive knowledge, metacognitive skills, executive skills, higher-order skills, metacomponents, metamemory are some of the terms that we are often using in association with metacognition. Metacognitive awareness means being aware of how you think. Metacognition is the awareness of one's thinking and the strategies one is using. It enables students to be more mindful of what they are doing, and why, and of how the skills they are learning might be used differently in different situations. The investigators in this paper try to analyze the metacognitive awareness of secondary school students. The investigators use a standardized awareness inventory for checking the metacognitive awareness of secondary school students. The study tries to find out whether there exists any significant difference between the various sub samples Gender, Locality and Type of Management of school based on their metacognitive awareness. The investigators use appropriate statistical techniques for the data collection and analysis of the data.
\end{abstract}

Keywords Metacognitive Awareness, Metacognitive Awareness Scale, Secondary School Students

\section{Introduction}

Meta cognition is often referred to as "thinking about thinking". Metacognition is a regulatory System that helps a person understand and control his or her own cognitive performance. Metacognition allows people to take charge of their own learning. sometimes people use the phrase 'going meta' when talking about metacognition, referring to the process of stepping back to see what you are doing, as if you were someone else observing it. "Going meta" means becoming an audience of your own performance- in this case, your own intellectual performance.

"Metacognition was originally referred to as the knowledge about and regulation of one's own cognitive activities in learning processes" [3](Flavell, 1979; Brown, 1978)

"Metacognition involves awareness of how they learn, an evaluation of their learning needs, generating strategies to meet these needs and then implementing the strategies" [4] (Hacker, 2009).

Metacognition is most commonly divided into two distinct, but interrelated areas. John flavell, one of the first researchers in metacognition and memory, defined these two areas as metacognitive knowledge- awareness of one's thinking- and metacognitive regulation- the ability to manage one's own thinking processes. These two components are used together to inform learning theory. Flavell ${ }^{[3]}$ (1979) describes three kinds of metacognitive knowledge:

- Awareness of knowledge- it involves understanding what one knows, what one does not know, and what one wants to know. This category may also include an awareness of other's knowledge.

- Awareness of thinking- understanding cognitive tasks and the nature of what is required to complete them.

- Awareness of thinking strategies- understanding approaches to direct learning.

Questions that explicitly help students think about, "How do I study best?" or "What kinds of tools help me learn?" all engage metacognitive knowledge. This can range from information that helps students assess their own abilities and intelligences to reflections on specific learning processes students tends to use in different situations. Metacognitive regulation involves the ability to think strategically and to solve problems, set goals, organize ideas, and evaluate what is known and not known. It also involves the ability to teach to others and make thinking process visible.

When a student has information about his thinking, he is 
able to use this information to direct or regulate his learning. This kind of metacognition is also referred to as "executive control". Successful learners typically use metacognitive strategies whenever they learn. But they may fail to use the best strategy for each type of learning situation. Here are some metacognitive skills that each student may follow.

- Knowing your limits - knowing the limits of one's own memory for a particular task and creating a means of external support.

- Self-monitoring - self-monitoring one's learning strategy, such as concept mapping, and then adapting the strategy if it is not effective.

- Modify - noticing whether one comprehend something one just read and then modifying approach if one did not comprehend it.

- Skimming - choosing to skim subheadings of unimportant information to get to the information one need.

- Rehearsing - repeatedly rehearsing a skill in order to gain proficiency.

- Self-test - periodically doing self-tests to see how well you learned something.

\section{Need and Significance of the Study}

Generally we do not know what we are doing when we do it, but it is very hard to improve a process that we are engaged in if we do not have a sense of what we are doing in the moment. If one aim of schooling is to prepare children to be lifelong learners, then it is important to help students become aware of themselves as learners and to take control of their own activities. The vast majority of students spontaneously pick up metacognitive knowledge and skills to a certain extent from their parents, their peers and especially from their teachers. However students show a considerable variation in their metacognitive ability. Learners often show an increase in self-confidence when they build metacognitive skills. Self-efficacy improves motivation as well as learning success.

Schwartz \& et.al (2004) freely explored a science Web site structured either in an outline (linear) format or "puzzle" (non-linear) format for 2.5 hours. Subjects then engaged in tasks involving locational memory and informational recall. The results indicate that presence of metacognitive skills was a necessary but not sufficient condition for learning in hypermedia environments; the navigational structure of the Web site also was important. Metacognitive skill (as measured by the Junior Metacognitive Awareness Inventory (Jr. MAI) (Sperling, Howard, Miller, \& Murphy, 2002) and the How I Study Questionnaire (HISP) (Fortunato, Hecht, Tittle, \& Alvarez, 1991) was not a significant predictor of measures of retention within an outline structure (where the conventional structure did not stimulate meta-cognitive knowledge), while metacognition was a significant predictor of informational recall within the puzzle structure (which required active meta-cognitive knowledge to make meaning within the unfamiliar structure). The results point to the need for instructional designers to consider the structure of Web sites, with particular emphasis on the use of recognizable conventions, in order to reduce the metacognitive demands upon working memory involved in deciphering the structure.

Ellery (2008) found that Strategic and well-planned use of feedback in the assessment process is key to promoting learning. The author evaluated the role a two-stage test process played in guiding and assisting student learning in a second-year module at the University of KwaZulu-Natal, South Africa. Having been provided with verbal and written feedback without grades from the first test, students were given the opportunity to write a different, second test, and each was required to choose which one was graded. Students were generally very positive about the assessment process, most participated willingly and fully, many learned differently for the second test, and there was evidence of meta-cognitive awareness and understanding. Despite this, a number of students experienced difficulty and frustration in judging the quality of their work.

Oviatt \& Cohen (2010) discussed about educational interfaces that facilitate communicative actions involving representations central to a domain can maximize students' effort associated with constructing new schemas. High school students' ability to solve a diverse range of biology problems was compared over longitudinal sessions while they used: (1) hardcopy paper and pencil (2) a digital paper and pen interface (3) pen tablet interface, and (4) graphical tablet interface. Post-test evaluations revealed that time to solve problems, meta-cognitive control, solution correctness, and memory all were significantly enhanced when using the digital pen and paper interface, compared with tablet interfaces. The tangible pen and paper interface also was the only alternative that significantly facilitated skill acquisition in low-performing students. Paradoxically, all students nonetheless believed that the tablet interfaces provided best support for their performance, revealing a lack of self-awareness about how to use computational tools to best advantage.

Belet \& Guven (2011) designed the study as a descriptive survey study in order to determine primary education teacher trainees' epistemological beliefs; the use of metacognitive strategies; and the relationship between epistemological beliefs and metacognitive strategies. 820 primary education teacher trainees' were selected from the department of primary education at seven education faculties. The Epistemological Beliefs Scale and the Metacognition Inventory were used to collect the data. The results revealed that the beliefs of primary education teacher trainees' on "learning depends on effort" were developed/matured more in comparison to the beliefs on "learning depends on skills" and the beliefs on "there is a single truth." Significant differences were found among their beliefs in terms of gender, grade, and the university they attend; while no significant relationship was found between their academic achievement and beliefs. Results also revealed that among the metacognitive strategies they used the most, primary education teacher trainees' used "self control" "cognitive strategy", "self evaluation" and "self-awareness" 
respectively. Significant differences were found among metacognitive strategies they used in terms of gender, grade, and the university they attend while no significant relationship was found between their academic achievement and metacognitive strategies they used.

Alt (2015) examined how educational efforts based on constructivist theory were associated with the self-efficacy beliefs of students within higher education settings. Perceived constructivist pedagogical principles and academic self-efficacy were measured for a sample of 167 undergraduate college students studying in a Problem-Based Learning environment (PBL) informed by constructivist theory, and in a traditional lecture-based environment which used conventional instruction. Multivariate analysis of covariance, path analysis and regression analysis showed that students in the PBL course perceived the learning environment as more constructivists and having high academic self-efficacy relative to the lecture-based environment. The construct "motivation towards reflections and concept investigation" (the extent to which high-order meta-cognitive learning functions towards knowledge are stimulated) was the most dominant positive predictor of academic self-efficacy.

van de Kamp \& et.al (2015) aimed to examine the effects of explicit instruction of meta-cognition on students' divergent thinking. A quasi-experimental design was implemented with 147 secondary school students in visual arts education. In the experimental condition, students attended a series of regular lessons with assignments on art reception and production, and they attended one intervention lesson with explicit instruction of meta-cognition. Results showed that explicit instruction of meta-cognitive knowledge had a positive effect on fluency and flexibility, but not on originality. The study implies that in the domain of visual arts, instructional support in building up meta-cognitive knowledge about divergent thinking may improve students' creative processes.

Rico \& Ertmer (2015) examine the role of the instructor during student-centered approaches, specifically those that are problem-centered, to outline effective strategies that are valuable for facilitating discussions. After describing the role of the instructor in each phase of implementation, from planning to evaluation, they discussed specific strategies for facilitating effective discussions. Strategies identified as being successful in problem-centered discussions included meta- cognitive questioning, peer facilitation, and teacher training, to name a few.

Diaz (2015) examined the effects of metacognitive strategies to help beginning young learners with difficulties increasing and retaining vocabulary. This was a qualitative study in which participants first went through metacognitive strategy instruction to provide awareness of learning strategies. Following this instruction, students underwent a set of five interventions based on the cognitive academic language learning approach instructional model. These interventions, together with journaling progress, were used to train them in the use of the metacognitive strategies planning, monitoring, and evaluating. The findings showed that metacognitive strategy training has positively contributed to vocabulary acquisition skills, as participants were able to raise consciousness about some learning strategies and the use of metacognitive strategies to increase their vocabulary learning.

Karaali (2015) illustrated how metacognition can be incorporated into a repeated exercise in the mathematics classroom, through a specific case study in the context of a liberal arts mathematics course. Through the semester, students were asked weekly to evaluate their own progress and review their development in light of their personal goals. $\mathrm{He}$ observed positive affective changes (including engagement levels) in the students through the course of the semester. He argues that the weekly metacognitive and self-reflective activities helped students keep their focus on learning deeply and allowed them to remain engaged and motivated through the semester.

For all age groups, metacognitive knowledge is crucial for efficient independent learning, because it fosters forethought and self-reflection. Good metacognitive thinkers are also good intentional learners. That is, they are able to direct their learning in the proper ways to build understanding. They know when to use strategies and how to use them. They are able to redirect the normal frustration that occurs when things are confusing or are not initially productive into further learning and research strategies. In this context the investigators got an interest in the area metacognitive awareness. From the reviews obtained also showed that Meta cognition improves the learning ability, retention and achievement. Investigators decided to check the level of metacognitive awareness of secondary school students. Investigators thought so because if the level of metacognitive awareness of secondary school students were found out, then it would be helpful for the teachers to guide them in proper way by means of appropriate instructional teaching strategies and provide appropriate techniques to students so that their metacognitive skills may develop which will enhance learning of concepts in a better way.

\section{Objectives of the Study}

- To find out the metacognitive awareness of secondary school students.

- To find out whether there exists any significant difference in the metacognitive awareness of secondary school students based on their locality.

- To find out whether there exists any significant difference in the metacognitive awareness of secondary school students based on their gender.

- To find out whether there exists any significant difference in the metacognitive awareness of secondary school students based on the type of management of the school.

\section{Hypotheses of the Study}

- The secondary school students of Kottayam district may have a higher level of metacognitive awareness. 
- There will be no significant difference in the metacognitive awareness of secondary school students based on the following sub samples;
(a). Locality
(b). Gender
(c). Type of management of school.

\section{Sample and Methodology}

The sample consists of 180 secondary school students from various schools of Kottayam district. The methodology adopted is normative survey method. ${ }^{[1]}$ (Best \& Kahn, 2007). The details of the sample selected for the study is as shown in Table 1 below.

\section{Tool for the Study}

The tool used was metacognitive awareness inventory prepared and standardized by Sindhu P.G (2011). It consists of thirty items following 5 point scale. The scale was standardized with reliability coefficient 0.742 which shows high reliability. Reliability is ensured using test-retest method. Validity is ensured as content validity.

\section{Statistical Techniques}

- Basic statistical techniques such as arithmetic mean median and standard deviation.

- $\chi^{2}-$ Test

- Significance of difference between the means.

\section{Methodology}

The investigators visited the schools mentioned in Table 1 and seeked the permission of school authorities to conduct the survey. The investigator selected standard IX of secondary level for the present study. Investigators selected 40 students each from rural secondary schools which are aided also. A total of 80 students fall under the category
Rural and Aided schools. Similarly the investigators selected 50 students each from government higher secondary schools which were urban also. A total of 100 students fall under this category. The investigators distributed Meta cognitive awareness Inventory among the selected sample of students. They were given proper instructions regarding how to fill the responses in the inventory. The investigators had given required time for students to record their responses in the inventory. After administration, the investigators collected the response sheets from students. The investigators valued the response sheets with a five point scale. The scores obtained by each student in the Metacognitive awareness inventory were encoded and undergone statistical calculations. Mean, standard deviation, percentiles and test of significant difference between means were calculated.

\section{Limitations of the Study}

The present study is limited to check the metacognitive awareness of secondary school students only. Moreover the study is limited to Kottayam district only.

\section{Analysis and Interpretation of the Data}

\section{Metacognitive Awareness of Secondary School Students}

The investigators categorized the whole sample used for the study in to Very Low, Low, Average, High, and Very High Metacognitive awareness groups based on the scores of Metacognitive awareness using Percentiles. P20, P40, P60, P80 percentiles were calculated and the students who scores less than P20 scores (100.20) is categorized as Very Low group, the students who scores in between P20 (100.20) and P40 (111.40) as Low, P40 (111.40) and P60 (118.00) as Average, P60 (118.00) and P80 (126.00) as High and greater than P80 (126.00) as Very High groups. The frequency of students and its percentage is given in table 2 .

Table 1. Sample selected for the study

\begin{tabular}{|c|c|c|c|c|}
\hline $\begin{array}{l}\text { Sl. } \\
\text { No. }\end{array}$ & Name of the School & Locality & $\begin{array}{c}\text { Type of } \\
\text { Management }\end{array}$ & $\begin{array}{c}\text { Number of } \\
\text { Students }\end{array}$ \\
\hline 1 & $\begin{array}{l}\text { St. Ephrem's Higher Secondary } \\
\text { School, Mannanam, Kottayam }\end{array}$ & Rural & Aided & 40 \\
\hline 2 & $\begin{array}{l}\text { Devi Vilasam Higher Secondary } \\
\text { School ,Kumaranelloor, Kottayam }\end{array}$ & Rural & Aided & 40 \\
\hline 3 & $\begin{array}{l}\text { Government Higher Secondary } \\
\text { School, Kudamaloor }\end{array}$ & Urban & Government & 50 \\
\hline 4 & $\begin{array}{c}\text { Government Higher Secondary } \\
\text { School, Arpookkara }\end{array}$ & Urban & Government & 50 \\
\hline
\end{tabular}

Table 2. Number and Percentage of different groups of Secondary School Students based on Metacognitive Awareness

\begin{tabular}{cccc}
\hline Group & Frequency & Percentage & $\chi^{2}$ \\
\hline Very Low awareness & 36 & 20 & 1.72 \\
Low Awareness & 36 & 20 & \\
Average Awareness & 42 & 29.3 & 17.2 \\
High Awareness & 31 & 19.4 \\
Very High Awareness & 35 & \\
\hline
\end{tabular}


From table 1 , it is clear that the obtained $\chi^{2}\left(\chi^{2}=1.72\right.$, $\mathrm{p}>$.05) shows the difference in the number of students in the distribution of students in each group is not significant. Hence it can be concluded that there exists no significant difference on the frequency of students in the distribution of students in each group. It was simply state that the secondary school students are identically distributed among each group. Or there is comparatively equal number of students included in each group. Also the table shows that the Average Awareness group contains comparatively high number of students (42). The figure 1, given below is clearly depicted this result.

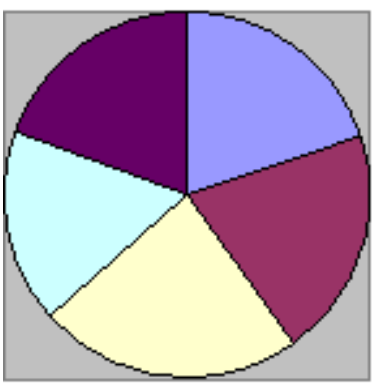

$\square$ Very low Awareness
$\square$ Low Awareness
$\square$ Average Awareness
$\square$ High Awareness
$\square$ Very High Awareness

Figure 1. Diagrammatic representation of distribution of students based on Mathematical Awareness

\section{Metacognitive Awareness of Secondary School Students Based on Their Locale}

In order to find out whether the metacognitive awareness of secondary school students vary with the locale, the mean and the standard deviation of the scores on the metacognitive awareness of secondary school students of the rural and urban locality were calculated. To know whether the two groups varied significantly in their scores on the metacognitive awareness, the t-test of non-equivalent groups was administered. The values thus obtained are tabulated below.

Table 3. Results showing significance of difference between means of scores of metacognitive awareness of secondary school students based on locality

\begin{tabular}{ccccc}
\hline Locale & Sample size & Mean & Standard deviation & t- value \\
\hline Rural & 80 & 113.48 & 13.69 & \\
Urban & 100 & 113.41 & 15.52 & $0.03^{*}$ \\
\hline
\end{tabular}

(* not significant at .01level of significance)

The mean and standard deviation of metacognitive awareness of rural secondary school students are 113.48 \& 13.69 and that of urban secondary school students are 113.41 $\& 15.52$ respectively. When their differences in means were tested for significance of difference between means, we get a $\mathrm{t}$ - value of 0.03 which is less than the values for .01 and.05 levels of significance. Hence it is inferred that there is no significant difference in the metacognitive awareness of secondary school students based on their locale.

\section{Metacognitive Awareness of Secondary School Students Based on Their Gender}

In order to find out whether the metacognitive awareness of secondary school students vary with the gender, the mean and the standard deviation of the scores on the metacognitive awareness of secondary school students - boys and girls were calculated. To know whether the two groups varied significantly in their scores on the metacognitive awareness, the t-test of non-equivalent groups was administered. The values thus obtained are tabulated below.

Table 4. Results showing significance of difference between means of scores of metacognitive awareness of secondary school students based on gender

\begin{tabular}{ccccc}
\hline Gender & Sample size & Mean & Standard deviation & t- value \\
\hline Boys & 107 & 110.63 & 14.67 & $1.07^{*}$ \\
Girls & 73 & 114.30 & 30.72 & \\
\hline
\end{tabular}

(* not significant at .01level of significance)

The mean and standard deviation of metacognitive awareness of secondary school boys are $110.63 \& 14.67$ and that of secondary school girls are $114.30 \& 30.72$ respectively. When their differences in means were tested for significance of difference between means, we get a t- value of 1.07 which is less than the values for .01 and.05 levels of significance. Hence it is inferred that there is no significant difference in the metacognitive awareness of secondary school students based on Gender.

\section{Metacognitive Awareness of Secondary School Students Based on Their Type of Management of Schools}

In order to find out whether the metacognitive awareness of secondary school students vary with type of management of the school, the mean and the standard deviation of the scores on the metacognitive awareness of Government and Aided secondary school students were calculated. To know whether the two groups varied significantly in their scores on the metacognitive awareness, the t-test of non-equivalent groups was administered. The values thus obtained are tabulated below.

Table 5. Results showing significance of difference between means of scores of metacognitive awareness of secondary school students based on type of management of schools

\begin{tabular}{ccccc}
\hline $\begin{array}{c}\text { Type of management } \\
\text { of school }\end{array}$ & $\begin{array}{c}\text { Sample } \\
\text { size }\end{array}$ & Mean & $\begin{array}{c}\text { Standard } \\
\text { deviation }\end{array}$ & $\begin{array}{c}\mathrm{t}- \\
\text { value }\end{array}$ \\
\hline Government & 100 & 113.41 & 15.52 & \\
Aided & 80 & 113.48 & 13.69 & \\
\hline
\end{tabular}

(* not significant at 0.01 level of significance)

The mean and standard deviation of metacognitive awareness of Government secondary school students are $113.41 \& 15.52$ and that of Aided secondary school students are $113.48 \& 13.69$ respectively. When their differences in 
means were tested for significance of difference between means, we get a t- value of 0.03 which is not significant at 0.01 and 0.05 levels. Hence it is inferred that there is no significant difference in the metacognitive awareness of secondary school students based on type of management of the school.

\section{Major Findings}

- The secondary school students are identically distributed among each group in the Metacognitive Awareness.

- There is no significant difference in the metacognitive awareness of secondary school students based on their locale.

- There is no significant difference in the metacognitive awareness of secondary school students based on their gender.

- There is no significant difference in the metacognitive awareness of secondary school students based on type of management of the school.

\section{Educational Implications}

- Metacognitive activities that ask students to reflect on what they know, care about, and are able to do not only help learners to develop an awareness of themselves, but also give valuable information for their instruction.
- Teachers should know the individual differences in the level of Meta cognitive awareness in a class room and should be given the teaching by taking into consideration their individual differences so that by the effective instruction in the class rooms, their metacognitive ability may enhance well.

- The study shows that Gender, Locality and Type of Management do not influence the Metacognitive ability of students. So whatever needed are innovative teaching methods and learning activities that arouse and develop the Metacognitive level of students.

- Metacognitive ability should be developed among school students. Then only they can reflect on their learning methods, their performance in the class room activities and improve their academic achievements accordingly.

\section{Conclusions}

Activities that encourage a reflective and strategic stance towards learning should be embedded in the regular activities of a classroom. Such reflective activities are an add-on, which takes away from the ongoing reflection, evaluation, and revision, and being strategic about work. When teachers make aspects of learning and problem-solving visible, and help students identify their own strengths and strategies, they can have a lasting impact on how their students learn once they leave their classrooms. 


\title{
Appendix-I
}

\author{
SCHOOL OF PEDAGOGICAL SCIENCES \\ M.G. University. Kottayam \\ METACOGNITIVE AWARENESS INVENTORY
}

\section{Name of the Student:}

\section{Name of the School :}

The following statements are related to your learning techniques and about your learning ability. Think for a minute and respond to the statements. The responses should be as precise as possible. There is no discrimination as right or wrong responses. If you are strongly agreeing with a statement, then put a tick $(\checkmark)$ mark corresponding to the column for strongly agree. Similarly put the tick marks in the columns for agree, not decided, disagree and strongly disagree according to your choice.

\begin{tabular}{|c|c|c|c|c|c|c|}
\hline Sl. No. & Statement & $\begin{array}{c}\text { Strongly } \\
\text { agree }\end{array}$ & Agree & $\begin{array}{c}\text { Not } \\
\text { decided }\end{array}$ & Disagree & $\begin{array}{l}\text { Strongly } \\
\text { disagree }\end{array}$ \\
\hline 1 & $\begin{array}{c}\text { When confronting with a problem, I often compare it with the problems } \\
\text { which I have previously solved. }\end{array}$ & & & & & \\
\hline 2 & When learning a new content, I compare it with the previously learned things. & & & & & \\
\hline 3 & I choose different learning methods according to the learning area. & & & & & \\
\hline 4 & I usually follows a strict time table for the studies. & & & & & \\
\hline 5 & Whenever taking a decision, I think at least twice about it. & & & & & \\
\hline 6 & $\begin{array}{l}\text { I often tries to complete my assignments and learning activities within the } \\
\text { time schedule. }\end{array}$ & & & & & \\
\hline 7 & After learning, I try to revise the central ideas in the content. & & & & & \\
\hline 8 & $\begin{array}{l}\text { I always try to discuss and solve the doubts related to the learning area with } \\
\text { my teachers and friends. }\end{array}$ & & & & & \\
\hline 9 & $\begin{array}{c}\text { I start learning only after getting a clear picture about the content to be } \\
\text { learned. }\end{array}$ & & & & & \\
\hline 10 & $\begin{array}{l}\text { When confronting with a problem situation, I always thinks about alternate } \\
\text { ways for solving it. }\end{array}$ & & & & & \\
\hline 11 & I always accept the innovative changes occurring in the society. & & & & & \\
\hline 12 & $\begin{array}{l}\text { As a student, I always critically analyze the ability of myself in learning } \\
\text { activities. }\end{array}$ & & & & & \\
\hline 13 & I always try to improve myself. & & & & & \\
\hline 14 & $\begin{array}{l}\text { I have the ability to completely concentrate on my learning activities in spite } \\
\text { of all the disturbing situations. }\end{array}$ & & & & & \\
\hline 15 & $\begin{array}{c}\text { Before starting the study, I collect all the relevant and recent information } \\
\text { about the content. }\end{array}$ & & & & & \\
\hline 16 & $\begin{array}{l}\text { After the successful completion of each learning task, my self confidence } \\
\text { increases. }\end{array}$ & & & & & \\
\hline 17 & $\begin{array}{l}\text { I always ask myself as whether I have gone for all other possibilities before } \\
\text { selecting a final solution. }\end{array}$ & & & & & \\
\hline 18 & I find happiness in collecting information about interesting learning areas. & & & & & \\
\hline 19 & I am efficient in finding and rectifying my own weaknesses. & & & & & \\
\hline 20 & I split the learning task into simple units. & & & & & \\
\hline 21 & I evaluate the ability of myself as a student in solving the learning tasks. & & & & & \\
\hline 22 & I change the speed and time of learning according to the learning contents. & & & & & \\
\hline 23 & Whenever doing a task, I completely engage in it. & & & & & \\
\hline 24 & $\begin{array}{l}\text { I regularly assess my learning efforts as whether I am going in the right way } \\
\text { or not. }\end{array}$ & & & & & \\
\hline 25 & $\begin{array}{l}\text { I control my emotions and wishes as they will hinder me from reaching the } \\
\text { learning goal. }\end{array}$ & & & & & \\
\hline 26 & $\begin{array}{l}\text { After completing a learning task, I always ask myself as is there any other } \\
\text { ways for solving the same task. }\end{array}$ & & & & & \\
\hline 27 & I try to do the allotted learning tasks as successful as possible by me. & & & & & \\
\hline 28 & I likes to collect meaningful and important information. & & & & & \\
\hline 29 & $\begin{array}{l}\text { Before beginning a learning activity I always try to read the instructions } \\
\text { carefully }\end{array}$ & & & & & \\
\hline 30 & I consider my failures as mile stones towards success. & & & & & \\
\hline
\end{tabular}




\section{REFERENCES}

[1] Best, J.W., \& Kahn, J.V. (2007). Research in education. New Delhi: Prentice hall of India.

[2] Dunlosky, J., \& Metcalfe, J. (2009). Metacognition. New Delhi: Sage publications.

[3] Austin, K., Cheung, M., Martin, D., \& et al. (2000). Thinking about thinking: Metacognition. Retrieved from www.learner.org/courses/learningclassroom/support/09_ metacog.pdf.

[4] Veenman, M.V.J., Bernadette, H.A.M., \& Afflerbach, P. (2005). Metacognition and learning: conceptual and methodological considerations. Retrieved from www.gse.uci.edu/person/martinez_m/docs/mmartinez_metac ognition.pdf.

[5] Oviatt, S. L., \& Cohen, A. O (2010). Toward High-Performance Communications Interfaces for Science Problem Solving. (EJ905287).

[6] Ellery, K.(2008). Assessment for Learning: A Case Study Using Feedback Effectively in an Essay-Style Test.
(EJ803167).

[7] Belet, S. D., \& Guven, M. (2011). Meta-Cognitive Strategy Usage and Epistemological Beliefs of Primary School Teacher Trainees. (EJ919889).

[8] Schwartz, N.H. (2004). The Influence of Metacognitive Skills on Learners' Memory of Information in a Hypermedia Environment. (EJ683685).

[9] Alt, D. (2015). Assessing the Contribution of a Constructivist Learning Environment to Academic Self-Efficacy in Higher Education. (EJ1052700).

[10] van de Kamp, M., Admiraal, W., van Drie, J., \& Rijlaarsdam, G. (2015). Enhancing Divergent Thinking in Visual Arts Education: Effects of Explicit Instruction of Meta-Cognition. (EJ1052144).

[11] Rico, R., \& Ertmer, P. A. (2015). Examining the Role of the Instructor in Problem-Centered Instruction. (EJ1067331).

[12] Diaz, I. (2015). Training in Metacognitive Strategies for Students' Vocabulary Improvement by Using Learning Journals. (EJ1051498).

[13] Karaali, G. (2015). Metacognition in the Classroom: Motivation and Self-Awareness of Mathematics Learners. (EJ1060949). 